\title{
МЕХАНИЧЕСКАЯ УСТОЙЧИВОСТЬ И АВАРИЙНОСТЬ ДРЕВЕСНЫХ РАСТЕНИЙ, ПРОИЗРАСТАЮЩИХ ВДОЛЬ УЛИЦЫ КИРОВА ГОРОДА ДОНЕЦКА
}

\begin{abstract}
MECHANICAL STABILITY AND ACCIDENT
RATE OF WOODY PLANTS GROWING
ALONG KIROV STREET OF DONETSK CITY
V. Kornienko
A. Yaitsky
Summary. The paper gives the research results of the influence of anthropogenic load on the mechanical stability, accident rate and viability of woody plants in a large industrial area (Donetsk city). A vibration-acoustic noise measurement of in the studied afforestations showed an excess of the dose limits, which may affect durability of the trees; nevertheless the latter effectively reduce the level of acoustic noise. Trees of the genus Aesculus hippocastanum L. are found to be highly viable in both growing conditions, near the motorway and at a distance (they showed good condition). The species of Populus bolleana Lauche and Populus simonii Carriere had a satisfactory condition (4-5 points in ranking). Unsatisfactory condition were characteristic for Acer platanoides L., Fraxinus excelsior L., Fraxinus pennsylvanica Marshall, Robinia pseudoacacia L. The mechanical stability of Acer platanoides L. was the highest among all the studied species: $\mathrm{d} / \mathrm{I}$ (ratio of diameter to trunk length) $=0,05$; El (bending stiffness) $=41 \times 10^{6}$; RRB (relative bending resistance) $=10.1 \times 10^{4} ; \mathrm{mcr}$ (critical mass) $=150 \times 10^{4}$. The average values of mechanical stability that characteristic for Populus bolleana Lauche, Fraxinus excelsior L., Fraxinus pennsylvanica Marshall are: $\mathrm{d} / \mathrm{I}=0,04 ; \mathrm{El}=63 \times 10^{6} ; \mathrm{RRB}=4,3 \times 10^{4} ; \mathrm{mcr}=3.2 \times 10^{4}$. The following species had low values in the intraspecific comparison of mechanical stability parameters: Aesculus hippocastanum L., Robinia pseudoacacia L., Populus simonii Carriere $\left(\mathrm{d} / \mathrm{I}=0,04 ; \mathrm{El}=6,0 \times 10^{6}\right.$; $\left.\mathrm{RRB}=3,6 \times 10^{4} ; \mathrm{mcr}=1,8 \times 10^{4}\right)$. A high degree of accident rate for plants growing in an urban environment was detected for Fraxinus excelsior L., Fraxinus pennsylvanica Marshall, Robinia pseudoacacia L. and Acer platanoides L. The average degree of accident is typical for trees of the genus Populus L. (Populus bolleana Lauche and Populus simonii Carriere). Aesculus hippocastanum L. trees had a low degree of accident rate.
\end{abstract}

Keywords: mechanical stability; accident rate of trees; viability; vibration-acoustic noise; traffic flow intensity; morphometric coefficient.

\author{
Корниенко Владимир Олегович \\ Старший преподаватель, ГОУ ВПО «Донечкий \\ начиональный университет» \\ kornienkovo@mail.ru \\ Яицкий Андрей Степанович \\ Старший преподаватель, ФГБОУ ВО «Самарский \\ государственный сочиально-педагогический \\ университет» \\ yaitsky@sgspu.ru
}

Аннотация. В работе представлены результаты исследований влияния антропогенной нагрузки на механическую устойчивость, аварийность и жизнеспособность древесных растений в условиях крупного промышленного города (на примере г. Донецка). Определение вибрационно-акустического шума в исследованных насаждениях показали превышение ПДУ, что, возможно, влияет на долговечность зелёных насаждений, но при этом деревья эффективно снижают уровень акустического шума. Высокой жизнеспособностью отмечены деревья вида Aesculus hippocastanum L., как в условиях произрастания вблизи автомагистрали, так и при удалении от неё (хорошее состояние). Удовлетворительным состоянием обладали виды Populus bolleana Lauche и Populus simonii Carriere (4-5 баллов). Неудовлетворительное состояние отмечено у Acer platanoides L., Fraxinus excelsior L., Fraxinus pennsylvanica Marshall, Robinia pseudoacacia L. Механическая устойчивость Acer platanoides L. была наивысшей среди всех изученных видов (d/l (отношение диаметра к длине ствола) = 0,05; El (жесткость на изгиб) $=41 \times 10^{6}$; RRB (относительное сопротивление изгибу) $=10,1 \times 10^{4} ; \mathrm{mcr}\left(\right.$ критическая масса) $\left.=150 \times 10^{4}\right)$. (редние значения механической устойчивости характерны для Populus bolleana Lauche, Fraxinus excelsior L., Fraxinus pennsylvanica Marshall (d/l = 0,04; $\left.\mathrm{El}=63 \times 10^{6} ; \mathrm{RRB}=4,3 \times 10^{4} ; \mathrm{mcr}=3,2 \times 10^{4}\right)$. Низкими значениями при внутривидовом сравнении параметров механической устойчивости обладали виды: Aesculus hippocastanum L., Robinia pseudoacacia L., Populus

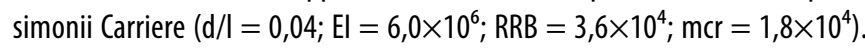
Высокая степень аварийности, для растений, произрастающих в условиях городской среды, выявлена у Fraxinus excelsior L., Fraxinus pennsylvanica Marshall, Robinia pseudoacacia L. и Acer platanoides L. Средняя степень аварийности характерна для видов рода Populus L. (Populus bolleana Lauche и Populus simonii Carriere). Низкой степенью аварийности обладали деревья Aesculus hippocastanum L.

Ключевые слова: механическая устойчивость; аварийность деревьев; жизнеспособность; вибрационно-акустический шум; интенсивность транспортного потока; морфометрический коэффициент. 


\section{Ввемение}

B условиях антропогенного загрязнения происходит нарушение физиолого-биохимических, клеточных, молекулярных и генетических процессов в растениях $[1 ; 2]$. Внешним результатом действия загрязнения являются изменения морфометрических параметров стволов и архитектоники кроны древесных растений, потеря жизнеспособности и как следствие снижение механической устойчивости и повышение аварийности деревьев при действии экологических факторов [3].

\section{Цель работы}

Оценка жизнеспособности, механической устойчивости и аварийности древесных растений, произрастающих в условиях урбодендроценозов, на примере города Донецка.

\section{Материалы \\ и мето $\Delta$ ы}

Мониторинговые исследования проводились с 2018 по 2021 гг. в г. Донецке, вдоль автомагистрали по ул. Кирова. В ходе исследования было оценено более 200 объектов древесных растений. Среди них выделены основные виды: клён остролистный (Acer platanoides L.), каштан конский обыкновенный (Aesculus hippocastanum L.), ясень высокий обыкновенный (Fraxinus excelsior L.), ясень пенсильванский (Fraxinus pennsylvanica Marshall), тополь Болле (Populus bolleana Lauche), тополь Симона (Populus simonii Carriere), poбиния псевдоакация (Robinia pseudoacacia L.).

\section{Территория}

проведения исслеАований

Исследуемая территория, на которой проводили дендрологические исследования, была разделена на 3 участка: 1 - «ост. ул. Скочинского - ост. ул. Бирюзова-2»; 2 - «ост. ул. Бирюзова-2 - ост. ул. Бирюзова-1»; 3 - «ост. ул. Бирюзова-1 - ост. ул. Алексинская» (рис. 1).

\section{Метолика оченки вибрашионно- акустического загрязнения на исследуемой территории}

Определение интенсивности движения производилось вблизи автомагистрали, в двух направлениях по улице Кирова, от остановки «ул. Скочинского» до остановки «ул. Алексинская». Интенсивность движения автотранспорта вдоль исследуемых участков на всей территории исследования оценивалась по количеству единиц автотранспорта определённого типа, проезжающих мимо точки измерения за единицу времени [4].

\section{$\triangle$ иагностика \\ механической устойчивости}

При визуальной оценке диагностическими критериями снижения устойчивости служат следующие признаки: во время ветра - значительное по амплитуде раскачивание ствола, скрипы, поднятие почвы над корневой системой; наличие сухих и усыхающих ветвей, повреждений ствола и ветвей, дупел; наклоненный ствол; асимметрия кроны; сильно удлиненные или изогнутые ветви, отходящие от ствола под углом около $90^{\circ}$. В условиях г. Донецка аварийными часто становятся такие ветви у вязов, ясеня зеленого, клена ясенелистного, лип, ив, ореха черного, тополя черного, тополя китайского и др. У таких пород, как дуб черешчатый, клен остролистный, платан и др., с прочной и упругой древесиной горизонтально растущие здоровые ветви не являются аварийными.

Продольный модуль упругости деревьев и кустарников измеряли стандартным методом по величине изгиба цилиндрической балки (части свежеспиленной ветви), защемленной одним концом, под действием нагрузки [5].

Для оценки прочности и параметров механической устойчивости древесных растений в урбанизированных городах использовали общепринятые методы [6]. В работе оценивались следующие параметры механической устойчивости: El - жесткость на изгиб, RRB относительное сопротивление изгибу, $\mathrm{m}_{c r}$ - критическая масса, $\mathrm{H} / \mathrm{H}_{c r}$ - высота к критической высоте дерева.

Оиенка аварийности деревьев в городской среде. При оценке древесных насаждений нами были использованы следующие методы: а) визуальный (осмотр дерева с земли, осмотр дерева с подъёмом на ствол, осмотр местности); б) ретроспективный (изучение исполнительной и проектной документации по строительным и ландшафтным работам, изучение ветровой особенности и нагруженности данного участка местности, выявление предыдущих случаев падения деревьев); в) инструментальный (взятие керна прирастным буром (Бурав Пресслера) и прямое испытание биомеханических свойств дерева (прочность и устойчивость)) [7].

Угол отхождения ствола от вертикали, а также скелетных ветвей измеряли в программе - Axio Vision Rel. 4.8. Были охвачены места насаждений вдоль автомагистрали ул. Кирова. 
Таблица 1. Бланк оценки механической устойчивости древесных растений на примере тополя Болле

\begin{tabular}{|c|c|}
\hline Параметр, ед. измерения & Показатель \\
\hline Вид & Populus bolleana Lauche \\
\hline Возраст, лет* & 51 \\
\hline Диаметр основания, $\mathrm{d}_{\text {осн }}$ м & 0,52 \\
\hline Диаметр на высоте 1,3 м, $\mathrm{d}_{b h}$ м & 0,47 \\
\hline Обхват ствола у основания $\mathrm{C}_{\text {осн }}$ M & 1,4 \\
\hline Обхват ствола на высоте $1,3 \mathrm{~m}, \mathrm{C}_{b h}, \mathrm{M}$ & 1,2 \\
\hline Высота дерева, Н, м & $17 \pm 0,2$ \\
\hline Угол наклона ствола, ${ }^{\circ}$ & 70 \\
\hline Балл жизненного состояния по Савельевой & 2 \\
\hline Морфологические повреждения ствола & морозобоины, потеки гнили \\
\hline Описание архитектоники кроны & $\begin{array}{l}\text { наблюдается асимметрия, неравномерное распределение } \\
\text { массы }\end{array}$ \\
\hline $\begin{array}{l}\text { Наличие морфогенетических и экзогенных повреждений листовой } \\
\text { пластинки, +/- }\end{array}$ & + \\
\hline Заселённость ствола вредителями, +/- & + \\
\hline Наличие дупел, +/- & - \\
\hline Ветровая особенность и нагруженность данного участка местности & $\begin{array}{l}\text { дерево слабо защищено от ветра, находится в сильно } \\
\text { продуваемом месте }\end{array}$ \\
\hline Режим посещения территории (рекреационная нагрузка) & средняя \\
\hline Направление возможного падения & в сторону автополотна, расстояние до цели 3-4 м \\
\hline Радиус ствола в месте забора керна, см & 28 \\
\hline Длина участка здоровой древесины на керне, $l$, см* & 10 \\
\hline Процент ядровой гнили,\%* & 64 \\
\hline Модуль упругости древесины, Е, ГН/м²* & 1,45 \\
\hline 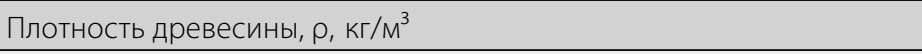 & 826 \\
\hline $\begin{array}{l}\text { Механическая устойчивость к статическим/ динамическим } \\
\text { нагрузкам согласно расчётам по биомеханике* }\end{array}$ & к статическим - да, к динамическим - нет \\
\hline Степень опасности** & высокая \\
\hline
\end{tabular}

Примечание. * - отмечены параметры, измерить которые возможно только современными методами исследования; ** - оценка степени опасности дерева производится путём сложения, с различными весовыми коэффициентами, числового выражения различных влияющих факторов.

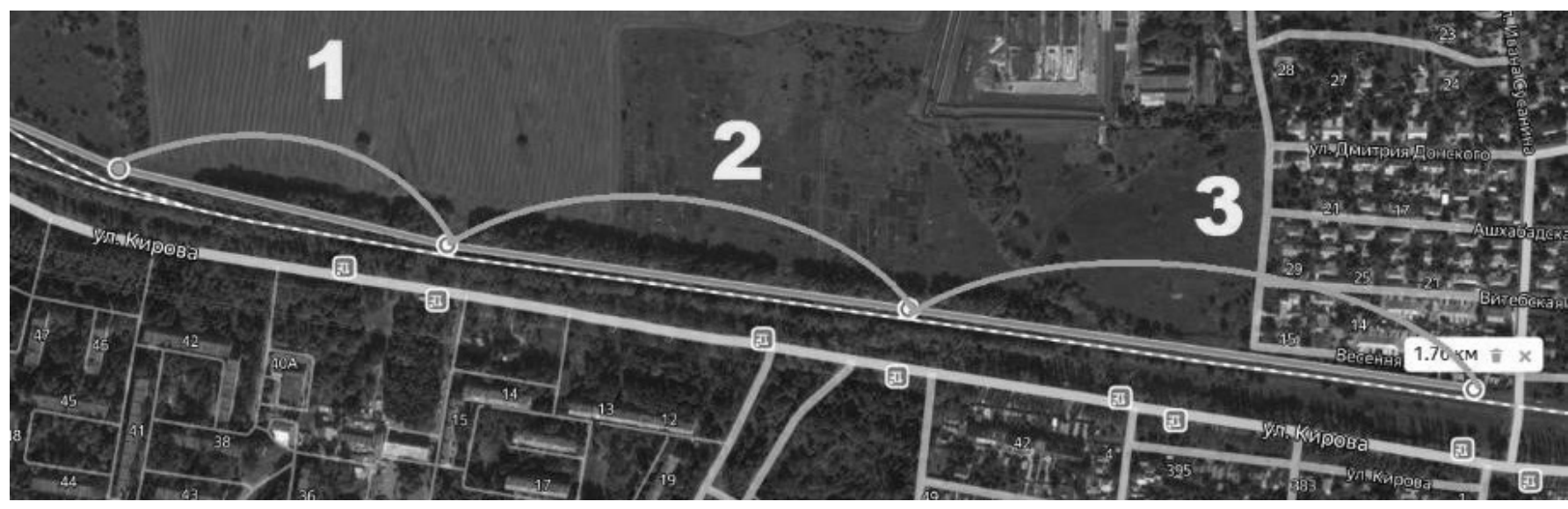

Рис. 1. Территория проведения дендрометрических исследований вдоль автомагистрали по ул. Кирова г. Донецка (ост. «ул. Скочинского» - ост. «ул. Алексинская») 
Таблица 2. Интенсивность транспортного потока вдоль ул. Кирова г. Донецка

\begin{tabular}{|c|c|c|c|c|c|c|}
\hline \multirow[t]{2}{*}{$\begin{array}{l}\text { Временной } \\
\text { интервал, час }\end{array}$} & $\begin{array}{l}\text { Легковые } \\
\text { иномарки }\end{array}$ & $\begin{array}{l}\text { Легковые } \\
\text { отечественные }\end{array}$ & \begin{tabular}{|l} 
Грузовые \\
легкие \\
(«Газель») \\
\end{tabular} & $\begin{array}{l}\text { Грузовые } \\
\text { тяжелые }\end{array}$ & $\begin{array}{l}\text { Автобусы (№ 66, } \\
\text { № 41, № } 8 \text {, № 22) }\end{array}$ & $\begin{array}{l}\text { Итого } \\
\text { в час }\end{array}$ \\
\hline & \multicolumn{6}{|c|}{ Количество, авт. } \\
\hline 06:00-07:00 & 220 & 140 & 15 & 10 & 17 & 402 \\
\hline 07:00-08:00 & 300 & 225 & 20 & 11 & 17 & 573 \\
\hline 08:00-09:00 & 320 & 240 & 23 & 15 & 17 & 615 \\
\hline 09:00-10:00 & 204 & 130 & 19 & 13 & 17 & 383 \\
\hline 10:00-11:00 & 135 & 145 & 15 & 10 & 17 & 322 \\
\hline 11:00-12:00 & 145 & 111 & 16 & 11 & 17 & 300 \\
\hline 12:00-13:00 & 170 & 125 & 11 & 15 & 17 & 338 \\
\hline 13:00-14:00 & 154 & 133 & 12 & 13 & 17 & 329 \\
\hline 14:00-15:00 & 245 & 127 & 10 & 14 & 17 & 413 \\
\hline 15:00-16:00 & 230 & 113 & 9 & 18 & 17 & 387 \\
\hline 16:00-17:00 & 277 & 186 & 18 & 14 & 17 & 512 \\
\hline 17:00-18:00 & 335 & 196 & 19 & 15 & 17 & 582 \\
\hline 18:00-19:00 & 320 & 178 & 25 & 20 & 17 & 560 \\
\hline 19:00-20:00 & 185 & 144 & 13 & 11 & 17 & 370 \\
\hline 20:00-21:00 & 205 & 124 & 15 & 10 & 17 & 371 \\
\hline 21:00-22:00 & 150 & 110 & 7 & 8 & 17 & 292 \\
\hline 22:00-23:00 & 84 & 115 & 9 & 7 & 17 & 232 \\
\hline Итого, авт. & 3679 & 2542 & 256 & 215 & 289 & 6981 \\
\hline Среднее, авт./час & 216 & 150 & 15 & 13 & 17 & 411 \\
\hline
\end{tabular}

Учитывались следующие показатели (табл. 1): критический возраст в условиях региона; угол наклона ствола от вертикали (оценивается по трём градациям: а) 10\% и менее; б) 11-40\%; в) более 40\%); наличие морозобоин, дупел, развилок, раковых повреждений, плодовых тел дереворазрушающих грибов, видимых повреждений корневой системы в результате строительных работ; архитектоника кроны (развитость кроны, асимметрия, сомкнутость, состояние листовых пластинок, усыхание ветвей); заселённость ствола вредителями; процент ядровой гнили (оценивается по трём градациям: а) $\geq 80 \%$; б) 40-79\%; в) 5-39\% (согласно методике [8]).

Также немаловажным является режим посещения территории (рекреационная нагрузка), направление возможного падения в сторону возможного скопления людей (рассматривается при выявлении скрытых гнилей); отношение диаметра к длине ствола; биомассы надземной части к критической массе с учётом угла наклона и ядровой гнили; механическая устойчивость к статическим нагрузкам; механическая устойчивость к динамическим нагрузкам [7].

Для статистической обработки данных использовали программы «Statistica 8» (StatSoft Inc.) и «Excel 2010» (Microsoft). Оценивались средние значения и стандартное отклонение от среднего. Также, по результатам регрессионного анализа оценивалась достоверность кривых в графиках зависимости параметров механической устойчивости древесных растений от морфометрических показателей [7].

\section{Результаты и обсужАения}

Оиенка интенсивности транспортного потока исследуемого участка. Анализ интенсивности транспортного потока исследуемого участка осуществлялся в разрезе основных категорий автомобилей, также учитывался временной интервал, в течение которого автомобили осуществляли движение.

Общее количество единиц транспортного потока в день составляет 6981 автомобилей (табл. 2). В среднем за 1 час вдоль исследуемой территории по ул. Кирова проезжает около 411 автомобилей.

Наибольшую долю нагрузки составляют легковые иномарки (3679 ед.) и легковые отечественные автомобили (2542 ед.) их доли составляют 53\% и 36\% соответственно. На долю грузовых легких автомобилей приходится 3,7\%, грузовых тяжелых - 3,1\%. Доля зашумления от рейсовых маршрутов составляет $4 \%$. В целом, транспортный поток с итоговым дневным значением в 6981 автомобиль, позволяет оценивать территорию как умеренно нагруженную. 
Таблица 3. Вибрационно-акустические параметры некоторых моделей автомобилей различной категории г. Донецка

\begin{tabular}{|c|c|c|c|c|}
\hline \multirow[b]{2}{*}{ Тип кузова } & \multirow[b]{2}{*}{ Модель автомобиля } & \multicolumn{3}{|l|}{$1, \mathrm{AБ}$} \\
\hline & & $\min$ & $\max$ & $\begin{array}{l}\text { среднее } \\
\text { значение }\end{array}$ \\
\hline Грузовой автомобиль отечественного производства & ГАЗ-3307 & 68,8 & 93,7 & 83,3 \\
\hline Городской автобус & Богдан & 63,7 & 86,0 & 74,7 \\
\hline Легковой автомобиль иностранного производства & Skoda Octavia & 47,9 & 73,8 & 59,9 \\
\hline Микроавтобус & ГАЗ-3221 & 47,2 & 79,0 & 62,5 \\
\hline Легковой автомобиль отечественного производства & BA3-2106 & 47,8 & 75,2 & 60,1 \\
\hline $\begin{array}{l}\text { Грузовой автомобиль отечественного производства } \\
\text { (тяжелый) }\end{array}$ & KAMA3-5308 & 48,4 & 83,3 & 62,6 \\
\hline Микроавтобус & УA3-2206 & 41,4 & 84,0 & 63,0 \\
\hline Легковой автомобиль иностранного производства & Hyundai Solaris & 46,8 & 73,5 & 60,0 \\
\hline Внедорожник & Mercedes-Benz W164 & 44,9 & 69,7 & 55,4 \\
\hline
\end{tabular}

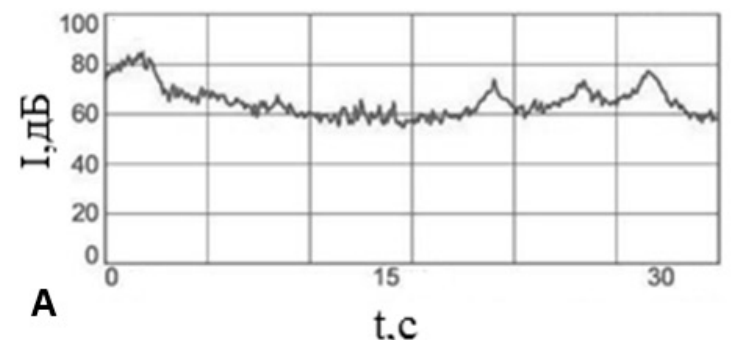

Рис. 2. Некоторые значения шумовой нагрузки, вызванной автомобильным потоком в будние дни по ул. Кирова г. Донецка. Примечания: А - замеры осуществлялись при интенсивности транспортного потока менее 400 ед./час; Б - замеры осуществлялись при интенсивности транспортного потока более 400 ед./час (в «час пик»)
Оиенка вибрачионно-акустического загрязнения территории. Оценку вибрационно-акустического загрязнения исследуемого участка по ул. Кирова выполняли путем анализа данных, полученных с помощью шумомера Benetech GM1351, при различном временном интервале (рис. 2).

Максимальная шумовая нагрузка, вызванная автомобильным потоком на исследуемой территории при интенсивности транспортного потока менее/более 400 ед./час (рис. 2: $A, Б$ ) составляет 89-91 дБ со спектром частот на максимуме энергии до 400 Гц, минимальное значение при этом составляет 44 дБ. Различие в вибрационно-акустических значениях заключаются только в продолжительности действия экологического фактора. Немаловажным фактором также является вид транспортного средства и его собственные вибрационно-акустические параметры, действие которых имеет различные биологические и экологические эффекты (табл. 3) [9].
Так, наибольший вклад в вибрационно-акустическое зашумление территории вносят грузовые автомобили отечественного производства $\left(\mathrm{I}_{\max }=93,7\right.$ дБ), городские автобусы $\left(\mathrm{I}_{\max }=86\right.$ дБ) и микроавтобусы $\left(\mathrm{I}_{\max }\right.$ $=84$ дБ). Расстояния до зеленых насаждений от автополотна по ул. Кирова приведены в табл. 4. Можно выделить 2 ряда линейных насаждений, где первый находится вблизи автомагистрали на расстоянии в среднем 2 м, а второй ряд на небольшом удалении - 5-6 м.

В связи с близким расположением древесных растений, вибрационно-акустический шум как постоянно действующий антропогенный фактор может влиять на жизнеспособность и общее состояние деревьев.

Представленность и жизнеспособность исследуемых видов по ул. Кирова г. Донецка. На исследуемой территории представленность видов, в зависимости от удаленности от автотрассы, отражена в табл. 5. Наибольшую долю в общей видовой совокупности 
Таблица 4. Расстояние от автополотна до объектов исследования по ул. Кирова г. Донецка

\begin{tabular}{|l|l|l|}
\multirow{2}{*}{ Участок } & Pасстояние, м \\
\cline { 2 - 3 } & $\min$ (1 ряд) & $\operatorname{max~(2~ряд)~}$ \\
\hline 1 — «ост. ул. Скочинского - ост. ул. Бирюзова-2» & 1,5 & 6,0 \\
\hline 3 - «ост. ул. Бирюзова-2 - ост. ул. Бирюзова-1» & 2,0 & 6,0 \\
\hline
\end{tabular}

Таблица 5. Представленность видов на исследуемой территории в зависимости от удаленности от автотрассы

\begin{tabular}{|c|c|c|c|}
\hline \multirow[b]{2}{*}{ Вид } & \multirow[b]{2}{*}{ Представленность,\% } & \multicolumn{2}{|c|}{$\begin{array}{l}\text { Жизнеспособность, балл } \\
\text { (ср. знач. } \pm \text { ст. откл.) }\end{array}$} \\
\hline & & $\begin{array}{l}\text { вблизи автотрассы } \\
\text { (до } 3 \text { м) }\end{array}$ & $\begin{array}{l}\text { на удалении } \\
\text { от автотрассы } \\
\text { (более } 3 \text { м) }\end{array}$ \\
\hline Acer platanoides L. & 5 & $2 \pm 1$ & $4 \pm 1$ \\
\hline Aesculus hippocastanum $\mathrm{L}$. & 6 & $6 \pm 1$ & $7 \pm 1$ \\
\hline Fraxinus excelsior $\mathrm{L}$. & 12 & $3 \pm 1$ & $4 \pm 1$ \\
\hline Fraxinus pennsylvanica Marshall & 13 & $3 \pm 1$ & $3 \pm 1$ \\
\hline Populus bolleana Lauche & 29 & $4 \pm 2$ & $5 \pm 1$ \\
\hline Populus simonii Carriere & 26 & $5 \pm 1$ & $5 \pm 1$ \\
\hline Robinia pseudoacacia $\mathrm{L}$. & 9 & $3 \pm 1$ & $3 \pm 1$ \\
\hline Всего: & 100 & & \\
\hline
\end{tabular}
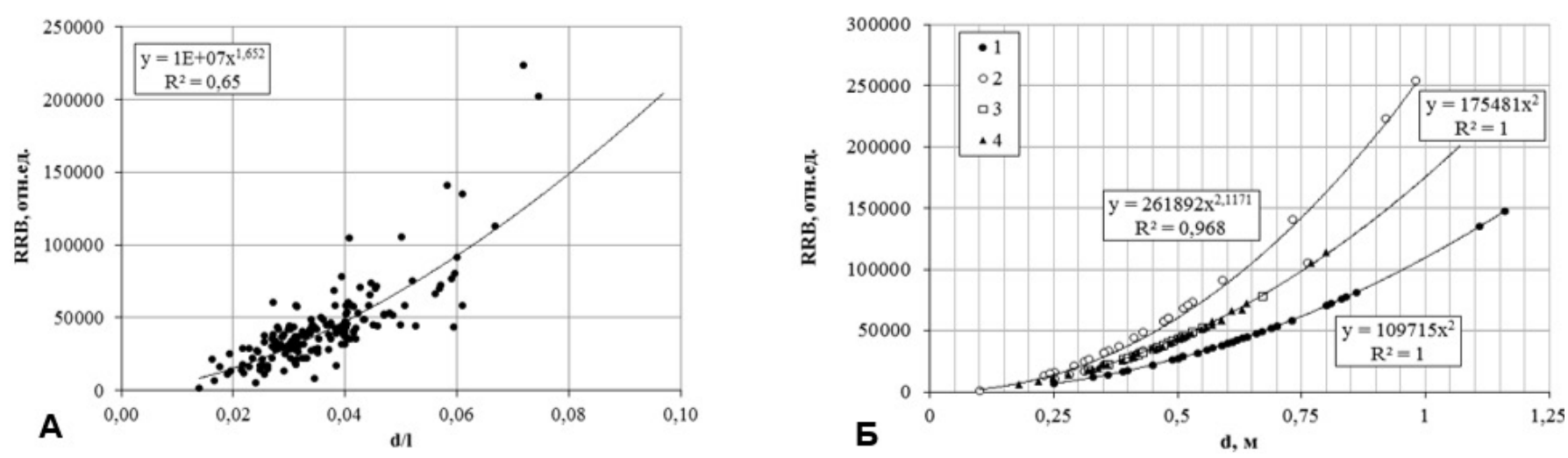

Рис. 3. Зависимость RRB от d/I (диаметр/длина) $(A)$ и d (диаметра) ствола (Б).

Примечания: 1 - значения для Populus bolleana Lauche; 2 -Acer platanoides L., Aesculus hippocastanum L., Robinia pseudoacacia L.; 3 - Populus simonii Carriere; 4 - Fraxinus excelsior L., Fraxinus pennsylvanica Marshall.

имеют такие виды как: Populus bolleana Lauche (29\%), Populus simonii Carriere (26\%), Fraxinus pennsylvanica Marshall (13\%), Fraxinus excelsior L. (12\%). Незначительную долю составляют представители Acer platanoides L. (5\%), Aesculus hippocastanum L. (6\%), Robinia pseudoacacia L. (9\%). Средневозрастное значение древесных насаждений на исследуемом участке составляет 40-45 лет.
Как вблизи (до 3 м), так и на удалении от автотрассы (более 3 м) наибольшую жизнеспособность, согласно шкале Савельевой, имеют представители вида Aesculus hippocastanum L., среднее значение жизнеспособности которых составляет 6 и 7 баллов соответственно. Вблизи автотрассы наименьшую жизнеспособность имеют представители вида Acer platanoides L., где среднее значение для вида составляет 2 балла (неудовлетво- 


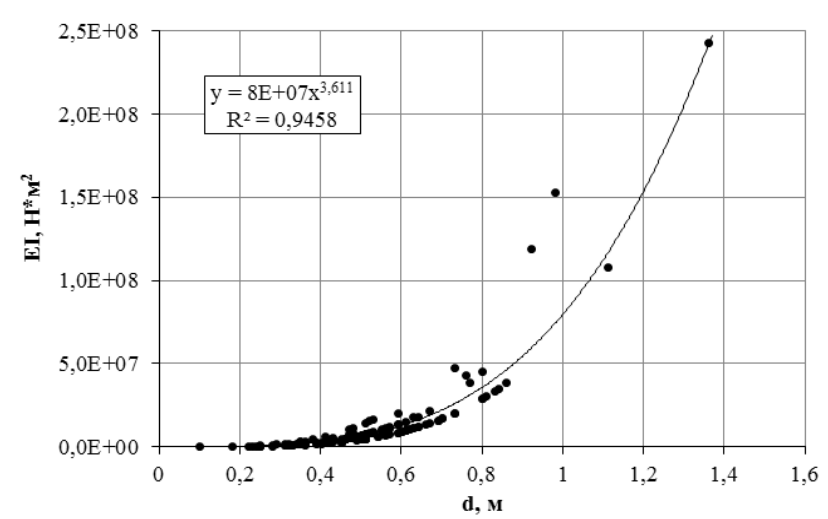

Рис. 4. Зависимость жесткости на изгиб (EI) от диаметра (d) ствола

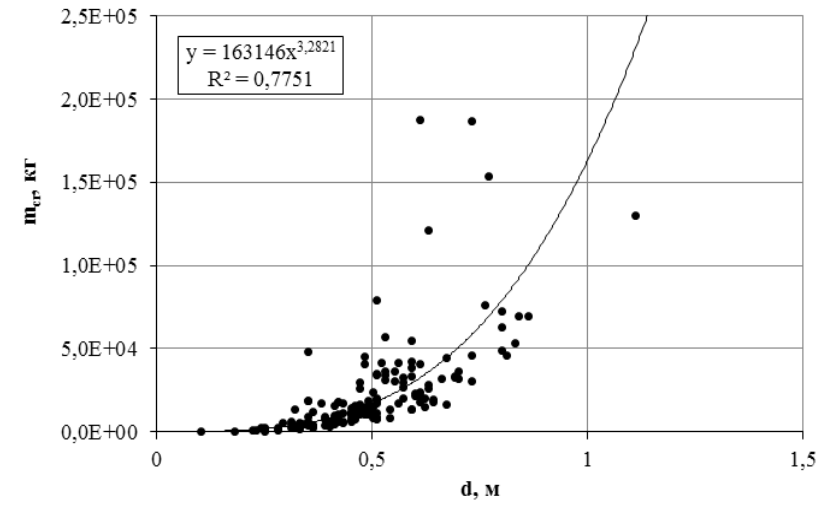

Рис. 5. Зависимость критической массы $\left(\mathrm{m}_{c r}\right)$ от диаметра $(\mathrm{d})$ ствола

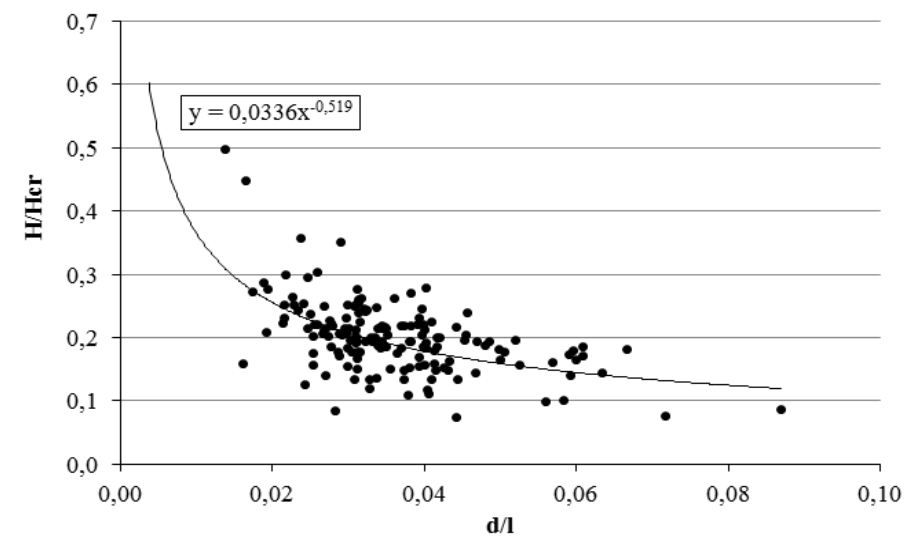

Рис. 6. Зависимость высоты к критической высоте дерева $\left(\mathrm{H} / \mathrm{H}_{c r}\right)$ от d/I (диаметр/длина) ствола

рительное состояние, частично сухостой), а во втором ряду, при удалении от автомагистрали - Fraxinus pennsylvanica Marshall и Robinia pseudoacacia L., среднее значение которых составляет 3 балла (неудовлетворительное состояние).

Механическая устойчивость древесных растений в городе Донецке, на примере ул. Кирова. Общевидовая зависимость параметра механической устойчивости относительного сопротивления изгибу ствола (RRB), носит степенной характер (коэффициент детерминации $\left.\left(R^{2}\right)=0,65\right)$. При значениях отношения диаметра ствола к его высоте (d/l) от 0,01 до 0,04 наблюдаются минимальные значения RRB (рис. 3: $A$ ). В диапазоне $\mathrm{d} / \mathrm{l}$ от 0,4 и выше, относительного сопротивления изгибу

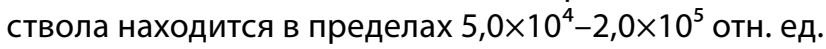

Рассматривая видовые зависимости относительного сопротивления изгибу ствола древесного растения, можно сделать вывод о высокой устойчивости Acer platanoides L., Aesculus hippocastanum L. и Robinia pseudoacacia L., произрастающих в урбодендроценозах города Донецка. Интересным является тот факт, что растения подразделяются на 3 класса по наклону кривой. Так, во втором классе (средняя устойчивость) находятся деревья Populus simonii Carriere, Fraxinus excelsior L. и Fraxinus pennsylvanica Marshall. Из общей выборки тополь Болле имеет наименьший наклон кривой, однако он компенсируется большими значениями диаметра ствола в возрасте 40-50 лет.

Для общевидовой характеристики зависимость параметра механической устойчивости жесткость на изгиб (EI), носит степенной характер $\left(R^{2}=0,95\right)$. При значения $\mathrm{d}$ от 0,2 до 0,7 наблюдаются минимальные значения El (рис. 3). В диапазоне d от 0,7 и выше, жесткость на изгиб находится в пределах $1,5 \times 10^{7}-5,0 \times 10^{8} \mathrm{H} \cdot \mathrm{M}^{2}$, что является высоким показателем механической устойчиво- 
Таблица 6. Оценка степени аварийности древесных растений, произрастающих в условиях городской среды

\begin{tabular}{|l|l|}
\hline Bид & Степень аварийности \\
\hline Acer platanoides $\mathrm{L}$. & высокая \\
\hline Aesculus hippocastanum $\mathrm{L}$. & низкая \\
\hline Fraxinus excelsior $\mathrm{L}$. & высокая \\
\hline Fraxinus pennsylvanica Marshall & высокая \\
\hline Populus bolleana Lauche & средняя \\
\hline Populus simonii Carriere & средняя \\
\hline Robinia pseudoacacia L. & высокая \\
\hline
\end{tabular}
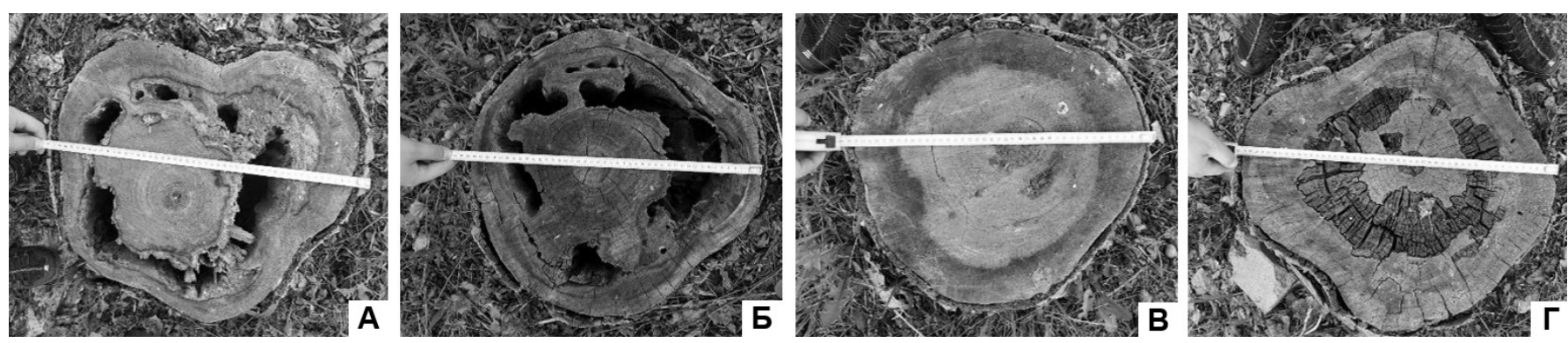

Рис. 7. Некоторые спилы растений Populus bolleana Lauche, имеющих высокую степень аварийности до момента ликвидации объекта. Примечания: A — № 5, D = 51 см, участок № 3, удаленность от трассы: 2 м (1 ряд); Б — № 17, D = 45 см, участок № 3, удаленность от трассы: 1,5 м (1 ряд); В № 18, D = 48 см, участок № 2, удаленность от трассы: 5 м (2 ряд); Г — № 42, D = 50 см, участок № 2,

удаленность от трассы: 5 м (2 ряд)

сти растений к действию статических и динамических нагрузок (рис. 4).

Общевидовая зависимость критической массы $\left(\mathrm{m}_{c r}\right)$ от отношения диаметра ствола к его высоте (d/l) носит степенной характер $\left(R^{2}=0,78\right)$. При значения $\mathrm{d}$ от 0,1 до 0,5 наблюдаются минимальные значения $\mathrm{m}_{c r}$ (рис. 5). В диапазоне $\mathrm{d}$ от 0,5 и выше, значения критической мас-

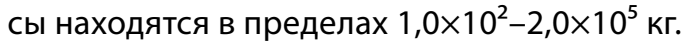

Общевидовая зависимость высоты к критической высоте дерева $\left(\mathrm{H} / \mathrm{H}_{c r}\right)$ от отношения диаметра ствола к его высоте (d/l) имеет степенной характер (рис. 6), однако значение достоверности является незначительным $\left(R^{2}=0,3\right)$. Из прогностической зависимости хода регрессии можно сделать вывод, что при значениях $\mathrm{d} / \mathrm{l}$ до 0,01 деревья будут иметь критические значения $(0,8-1,0)$ и оцениваться как механически неустойчивые. Однако в нашей выборке таких растений выявлено не было.

Оиеенка аварийности древесных растений в городе Донеике. Наибольшую степень аварийности на исследуемой территории имели представители видов Fraxinus excelsior L., Fraxinus pennsylvanica
Marshall и Robinia pseudoacacia L. (табл. 6). Это может быть связано с приближением к критическому значению возраста деревьев в условиях региона, нарушению физиолого-биохимических процессов в растениях [1] в результате чего происходит снижение их жизнеспособности, невыполнение ряда экологических функций и в крайнем случае выпадение из древостоя.

Среднюю степень аварийности имели виды Populus bolleana Lauche и Populus simonii Carriere. Хотя для некоторых растений рода Populus L. (17 деревьев), которые достигли критического возраста 50 и более лет, степень аварийности была оценена как высокая (рис. 7).

Наиболее устойчивым видом являлся Aesculus hippocastanum L. Деревья данного вида - в основном это растения, не имеющие серьезных повреждений ствола и кроны, кроме морозобоин, которые характерны для этого вида на юго-востоке степной зоны.

Отметим, что в зимний период (февраль) 2021 г коммунальной службой Кировского района г. Донецка были ликвидированы 14 объектов древесных растений вблизи автомагистрали по ул. Кирова, в связи с уча- 
стившимися случаями крушения деревьев. Все деревья тополя Болле на этом участке нами были оценены как аварийные с высокой долей вероятности облома. Распространение гнили в стволе растений показаны на рис. 7. Из анализа графического материала видно, что степень распространения гнили коррелирует с оценкой аварийности деревьев по использованной нами методике, включающей дендрологические и математические методы анализа.

\section{ВывО $\triangle \mathrm{b}$}

Высокой жизнеспособностью отмечены деревья вида Aesculus hippocastanum L., как в условиях произрастания вблизи автомагистрали, так и при удалении от неё (6-7 баллов). Удовлетворительным состоянием обладали виды Populus bolleana Lauche и Populus simonii Carriere (4-5 баллов). Неудовлетворительное состояние характерно для Acer platanoides L., Fraxinus excelsior L., Fraxinus pennsylvanica Marshall, Robinia pseudoacacia $\mathrm{L}$.
Механическая устойчивость Acer platanoides L. была наивысшей среди всех изученных видов $(\mathrm{d} / \mathrm{l}=$ 0,05; El $\left.=41 \times 10^{6} ; \mathrm{RRB}=10,1 \times 10^{4} ; \mathrm{m}_{c r}=150 \times 10^{4}\right)$. Средние значения механической устойчивости характерны для Populus bolleana Lauche, Fraxinus excelsior L., Fraxinus pennsylvanica Marshall $(\mathrm{d} / \mathrm{I}=0,04$; $\mathrm{El}=$ $63 \times 10^{6} ; \mathrm{RRB}=4,3 \times 10^{4} ; \mathrm{m}_{c r}=3,2 \times 10^{4}$ ). Низкими значениями при внутривидовом сравнении всех параметров механической устойчивости обладали виды: Aesculus hippocastanum L., Robinia pseudoacacia L., Populus simonii Carriere $\left(\mathrm{d} / \mathrm{l}=0,04 ; \mathrm{EI}=6,0 \times 10^{6} ; \mathrm{RRB}=3,6 \times 10^{4}\right.$; $\left.\mathrm{m}_{c r}=1,8 \times 10^{4}\right)$.

Высокая степень аварийности для растений, произрастающих в условиях городской среды, выявлена у Fraxinus excelsior L., Fraxinus pennsylvanica Marshall, Robinia pseudoacacia L. и Acer platanoides L. Средняя степень аварийности характерна для видов рода Populus L. (Populus bolleana Lauche и Populus simonii Carriere). Низкой степенью аварийности обладали деревья Aesculus hippocastanum L.

\section{ЛИТЕРАТУРА}

1. Поляков А.К. Интродукция древесных растений в условиях техногенной среды / под общ. ред. чл.- корр. НАН Украины А.З. Глухова. Донецк: Ноулидж, 2009. 268 c.

2. Alonso-Serra J. et al. Elimäki locus is required for vertical proprioceptive response in birch trees // Current Biology. 2020. Vol. 30, iss. 4. P. 589-599. D0I: 10.1016/j.cub.2019.12.016.

3. Корниенко В.О., Приходько С.А., Яицкий А.С. Оценка жизненного состояния древесных насаждений в условиях урбанизированной среды // Современная наука: актуальные проблемы теории и практики. Серия: Естественные и технические науки. 2020. № 03/2. С. 14-19.

4. ГОСТ 20444-85. Шум. Транспортные потоки. Методы измерения шумовой характеристики. М.: Издательство стандартов, 1985. 20 с.

5. Нецветов М.В., Суслова Е.П. Механическая устойчивость деревьев и кустарников к вибрационным нагрузкам // Промышленная ботаника. 2009. Вып. 9. C. $60-67$.

6. Корниенко В.О., Калаев В.Н., Елизаров А.О. Влияние температуры на биомеханические свойства древесных растений в условиях закрытого и открытого грунта // Сибирский лесной журнал. 2018. № 6. С. 91-102.

7. К Корниенко В.О., Приходько С.А. Новый методический подход к оценке механической устойчивости зелёных насаждений в городской среде // Самарский научный вестник. 2018. Т. 7, № 2 (23). С. 72-77. DOI: 10.17816/snv201872114.

8. Румянцев Д.Е. Выявление аварийных деревьев в урбанизированной среде: проблемы и перспективы [Электронный ресурс] // Дендрология и уход за деревьями в урбанизированной среде. - https://s.econf.rae.ru/pdf/2015/03/4337.pdf.

9. Нецветов М.В., Хиженков П.К., Суслова Е.П. Введение в вибрационную экологию. Донецк: Вебер, 2009. 164 с.

(с) Корниенко Владимир Олегович ( kornienkovo@mail.ru), Яицкий Андрей Степанович ( yaitsky@sgspu.ru ). Журнал «Современная наука: актуальные проблемы теории и практики» 